\title{
A review on the effect of carbon based nanofillers on the properties of elastomers
}

\begin{abstract}
Reinforced Rubber products are one of the most widely used composite materials in industries (automobile tires, hoses and conveyor belts). Reinforced rubber products consist of a low strength rubber matrix and a reinforcing material of high strength and stiffness. Rubber products reinforced with low volume fraction of nanofillers exhibit remarkable properties compared to rubber products reinforced with conventional fillers. The properties of composites depend upon the structure of the polymer matrix, nature of carbon based nanofillers and the method of preparation. By adding suitable carbon based nanofillers like graphite, graphene, graphene oxide, carbon nanotubes (CNT), fullerene, the mechanical, thermal, barrier and ageing properties of the polymer can be greatly improved. This review paper addresses some recent developments in rubber composites reinforced with carbon based nanofillers and the subsequent improvement of properties.
\end{abstract}

Keywords: rubber, nanofillers, nanocomposites, properties
Volume 3 Issue 3 - 2019

\author{
Gobinath Velu Kaliyannan,' Rajasekar \\ Rathanasamy,' Sathish KumarPalaniappan, ${ }^{2}$ \\ Mahesh Kumar KV, ${ }^{3}$ Moganapriya \\ Chinnasamy' \\ 'Department of Mechanical Engineering, Kongu Engineering \\ College, India \\ ${ }^{2}$ Department of Mining Engineering, Indian Institute of \\ Technology, India \\ ${ }^{3}$ Department of Mechatronics Engineering, Kongu Engineering \\ College, India
}

Correspondence: Rajasekar Rathanasamy, Department of Mechanical Engineering, Kongu Engineering College, Perundurai, Erode, India - 638 060, Email rajasekar.cr@gmail.com

Received: March 18,2019| Published: June 26, 2019
Abbreviations: $\mathrm{AC}$, active carbon; C60, fullerene; $\mathrm{CB}$, carbon black; CNTB, carbon nanotube bundles; CNTs, carbon nanotubes; CRGO, chemically reduced graphene oxide; CTAB, cetyltrimethylammonium bromide; CVD, chemical vapor deposition; DETA, dielectric thermal analyser; DMA, dynamic mechanical analysis; DSC, differential scanning calorimetry; EBT, entanglementtube model; EBT, Entanglement-tube model; EDX, X-ray analysis; EG, expended graphite; ENR epoxidized natural rubber; EPDM, ethylene-propylene-diene rubber; FC-CVD, floating catalyst chemical vapour deposition; F-CNTs, functionalized carbon nanotubes; FESEM, field emission scanning electron microscope; FGSs, functionalized graphene sheet; FTIR, fourier transform infrared spectroscopy; GNP, graphene nanoparticles; HNBR, Hydrogenated nitrile-butadiene rubber; HRH, hexamethylene tetramine; HRTEM, high resolution transmission electron microscope; HXNBR, hydrogenated carboxylated nitrile-butadiene rubber; ID, dband; IG, G band; IIR, butyl rubber; MD, machine direction; MEG, modified expanded graphite; MLGS, multi-layered graphenesheet; MPTMS, mercaptopropyltrimethoxysilane; MWCNTs, multi-walled carbon nanotubes; NBR, nitrile butadiene rubber; NR, natural rubber; OBDs, organic bistable device; PAC, polyaluminium chloride; PCR, polychloroprene rubber; PDMS, polydimethylsiloxane; Phr, perhundred rubber; PLA, polylactic acid; PR, petroleum resin; RGO, reduced graphene oxide; SA, stearic acid; SAXS, small angle $\mathrm{x}$-ray scattering; SAXS, x-ray scattering measurement; SBR, styrenebutadiene rubber; SE, shielding effectiveness; SEM, scanning electron microscope; SIC, strain-induced crystallization; SLES, sodiumlaurethsulfate; SRM, solidrocketmotor; SWNTs, singlewalled carbon nanotubes; TD, transverse direction; TEGO, thermallyexfoliated graphite oxide; TEM, transmission electron microscope; $\mathrm{Tg}$, transition temperature; TGA, Thermal gravimetric analysis; TGA, thermo gravimetric analysis; $\mathrm{TiO}_{2}$, titanium dioxide; TPNRs, thermoplastic natural rubber; UV, ultraviolet; WAXD, wide angle diffraction; XRD, X-ray diffraction; $\mathrm{ZnO}$, zinc oxide

\section{Introduction}

Nanoscience or Nanotechnology is rightly considered as a revolutionary science comprising many disciplines. The term Nano denotes the range of $1-100 \mathrm{~nm}$. The widespread application of Nanomaterials in various fields is recent; though the usage of such materials dates back to the beginning of $20^{\text {th }}$ century. Nano engineered polymeric composites are fast replacing conventional composites. Nanocomposites possess few advantages over conventional materials as follows.
A. Light weight.
B. Low cost.
C. Enhanced the mechanical and barrier properties.

According to a survey in 2006, the consumption of rubber is about 21.5 metric tonnes. Of the total consumption, Natural Rubber (NR) accounts for $43.1 \%$ and the Synthetic Rubber (SR) accounts for the remaining $(56.9 \%)$. Conventional fillers in the range of $20-40 \%$ should be added to obtain specific properties. The same properties can be obtained by adding a very low quantity of nanofiller (3-5\%). The major application of rubber is in the automobile industry (tires and tubes). They are also used in hoses, gaskets, oil seals, etc. The nanocomposites classified into three types based on the size dispersed particles in nanometer range as follows

a. Iso dimensional nanofillers

b. An elongated structure where only two dimensions are in nano scale.

c. Nanocomposites in sheet form where only one dimension is in nanometer scale

Rubber (elastomer) is extensively used due to its higher and flexible deformability. As the necessary strength and modulus of pure elastomer are low, a further reinforcing phase (filler) is needed for 
the practical use of rubber materials (matrix). Elastomer is mostly reinforced with $\mathrm{CB}$, fibers and silicates. The inclusive reinforcing belongings from these fillers materials are minimized due to their larger size and agglomeration, and request of the fine dispersed nanofillers into elastomer to reach beneficial physical and mechanical properties is becoming crucial. The different types of rubber properties are summarized in Table 1. The NR is a crucial material in industrial application like vehicle tires, oil seals and vibration isolation system due to good elastic property, and greater cracking resistance. ${ }^{2}$ The synthetic SBR is one of the broadly used for conveyor, footwear, production of automobile tires, hoses, belts, flooring and adhesive. EPDM is a mostly used synthetic rubber in quite few applications like automotive sealing; cover stripes, side walls of tyres, cables, wires, and hoses and also insulator. EPDM as an unsaturated polyolefin has been mostly used in constructing better performance nanocomposites due to its remarkable function and environmental properties. Rubber is regularly reinforced with mineral fillers to substantially expand the strong point and stiffness. Without the filler material in elastomer forming would yield resilience those products possess elastic properties but very less strength. The increase of property enhancement depends on different parameter including the size of particles, their degree of dispersion, their aspect ratio, and orientation of the rubber and the degree of bond with rubber chains. ${ }^{3}$ In this review, the belongings of adding carbon based fillers into rubber matrix in order to get different types of properties improvements are analysed.

Table I Properties of different rubber

\begin{tabular}{lllllll}
\hline S. No & Properties & Types of rubber & & & \\
& NR & SBR & EPDM & IIR & NBR \\
\hline 1 & Mechanical Strength & Excellent & Good & Fair $/$ Good & Fair / Poor & Good \\
2 & Operating Temperature & -45 to $95^{\circ} \mathrm{C}$ & -40 to $95^{\circ} \mathrm{C}$ & -50 to $140^{\circ} \mathrm{C}$ & -45 to $150^{\circ} \mathrm{C}$ & -35 to $/ 25^{\circ} \mathrm{C}$ \\
3 & Ozone/Weather Resistance & Poor $/$ Fair & Poor $/$ Fair & Excellent & Excellent & Fair \\
4 & Abrasion Resistance & Good/Excellent & Excellent & Fair & Good & Excellent \\
5 & Water Resistance & Good & Good & Excellent & Excellent & Good \\
6 & Oil Resistance & Poor & Poor & Poor & Poor & Excellent \\
7 & Low Temperature Flexibility & Good & Good & Good/Excellent & Good & Fair/Good \\
8 & Fuel Resistance & Poor & Poor & Poor & Poor & Good \\
9 & Resistance to Dilute Acid & Good & Fair & Excellent & Excellent & Excellent \\
10 & Impermeability to Gases & Fair & Fair & Good & Excellent & Good \\
11 & Flex Resistance & Excellent & Good & Fair & Good & Fair \\
12 & Adhesion & Excellent & Excellent & Good/Excellent & Excellent & Excellent \\
13 & Resilience & Good/Excellent & Fair & Good/Excellent & Good & Excellent \\
\hline
\end{tabular}

\section{Natural rubber nanocomposites}

Jeffery R Potts et al., ${ }^{1}$ found that dispersion of thermally-exfoliated graphite oxide was effective in thermoplastic polymer by melt processing. Natural rubber containing TEGO was prepared. Premixing (without use of solvents) the TEGO containing with natural rubber latex ready by an ultrasonically assisted latex co-coagulation method was followed by the lab two roll mill. The possessions were significantly enhanced compared to the thermally-exfoliated graphite oxide / Natural Rubber nanocomposite mixed only on the two- roll mill. As significant transmission electron microscope investigation proposed a less variation in dispersion in terminologies of an usual platelet aspect ratio, the enhancement of property in the L-TEGO/NR composites was attributed to a even distribution of TEGO platelets. At the time of ultrasonic treatment, TEGO in water did not induce a reliable suspension of exfoliated TEGO platelets. It was found efficient distribution of TEGO into NR matrix using traditional rubber handling apparatus, pre-mixing with latex or without the use of solvents, posed a significant challenge. Asish Malas et al., ${ }^{2}$ Nanosized expended graphite revealed the same layered network like organoclay and huge expansion ratio so that elastomer chain can be conveniently introduced. To enhance the distribution of expended graphite in elastomeric mediums, mainly the surface alteration of the EG was carried out and after the modified MEG/ENR composites were fabricated by solution mixing method. Next that the MEG/ENR composites were prepared with NR in the existence and nonappearance of carbon black in a lab two roll mill. WAXD and HR TEM investigate of the nanocomposites explained that modified expanded graphite was introduced and exfoliated in the natural rubber matrix. Scanning electron microscope appearance of the composites displayed exact harsh surface than neat NR matrix. expended graphite/modified expanded graphite loaded nanocomposites displayed dramatically increase in the storage modulus and mechanical properties than the neat rubber. Modified expanded graphite and modified expanded graphite/Carbon black incorporated NR vulcanizates with compatibilizer displayed enhanced mechanical, dynamic mechanical and curing performance than the expended graphite and expended graphite /carbon black loaded natural rubber compound.

Marianella Hernandez et al., ${ }^{3}$ prepared NR containing FGSs by via conventional two-roll mill. Enhanced cross-linking reaction, the improved electrical conductivity and improved mechanical behavior of NR nanocomposite resulted due to rubber- to- filler interactions. The molecule dynamics was not affected by nanofiller. The exfoliation of FGS was confirmed by the changes on the interlayer distance determined from the X-ray diffraction data. XPS spectrum 
indicated that functional groups were attached to the layer. The strong rubber-to-filler interaction occurred due to the presence of defects, irregularities. The important parameter for increasing dynamics was the presence of vulcanizing additives. Omar A Al-Hartomy et al., ${ }^{4}$ The difficult dispersion of carbon nanotubes in the rubber matrix and high price inhibited the development of CNT based materials. Graphene based materials dispersed easily in the polymer matrix. Graphene based materials possess high aspect ratio and low density. Dispersion of graphene into NR was found to intensely improve the mechanical, electrical, and electronic properties. Natural rubber containing graphene nanoparticles in the range of 2.0 to $10.0 \mathrm{Phr}$ were analysed in the frequency range from $(1-12 \mathrm{GHz})$. Increase in the frequency and filler amount of nanocomposites slightly increased the dielectric permittivity. Electric loss angle tangent mainly depended on the level of filler amount contained in the polymer matrix. Less amount of filler in polymer matrix slightly affected the electric loss angle tangent Increasing the filler amount and frequency increased the reflection coefficient. The attenuation coefficient did not depend on frequency and loading filler amount range from $1-6 \mathrm{GHz}$, then increased slightly in the 6-9 GHz range, but frequency on the $9-12 \mathrm{GHz}$ range its improved dramatically. The frequency and filler had direct impact on the electromagnetic shielding effectiveness as well as upon the replication and attenuation factors. The S.E value ranged from 10-30 dB. It was evident that natural rubber with graphene exhibited better dielectric and microwave properties compared to the natural rubber with carbon nanotubes. Jinrong Wu et al., ${ }^{5}$ fabricatedGE/ NR nanocomposites by using a changed (modified) latex mixing technique. The effect of GE on the vulcanization kinetics of NR with sulfur curing method was analyzed. Figure 1 shows that the Schematic illustration of the network structures of pure NR (a) and graphene filled natural rubber nanocomposites ${ }^{5}$ (b) It was found that on adding GE, the introduction period of the vulcanization method extraordinarily depressed, because the vulcanization rate increased at lower amount of graphene loading and then contained. The optimum cure time reduced greatly at initial stage and afterwards displayed a slight increase with increasing GE loading. While the crosslink density of NR improved monotonically, whereas GE took part in the vulcanization processes The vacant natural rubber and GE/NR composites with amount of GE loading $\leq$ $0.3 \mathrm{phr}$ (per hundred rubber) showed a only exothermal peak for the duration ofvulcanization process, which though separated into peaks at high amount of GE loading. So, the two peaks were associated to double reaction phases, (ie) chemical reaction regulating phase and second diffusion regulating phase. The chemical regulating phase had low level of activation energy compared to the diffusion regulating phase. Adding of GE reduced the level of activation energy of the former phase, at the same time had opposed effect on the activation energy of the latter phase. At the final stage of desirable mechanism was reported to explain the accelerating effect of GE on NR.

Bulent Ozbas et al., ${ }^{6}$ prepared NR containing functionalized graphene sheet by latex mixing. The SIC and mechanical properties of NR/FGS composites were studied. Functionalized graphene are single sheets of graphene with length several hundred nanometers and thickness $1.5 \mathrm{~nm}$. The impact of functionalized graphene sheet and $\mathrm{CB}$ on strain-induced crystallization of natural rubber was related with coupled tensile tests and XRD. Measurement of the stress and crystallization of natural rubber in real time was done by synchrotron $\mathrm{X}$-ray scattering equipment. The stress- strain profile of one weight percentage of FGS filled NR was equal to $16.0 \mathrm{wt} \%$ Carbon black with filed natural rubber, with the functionalized graphene sheet exhibiting $40 \%$ maximum ultimate strength and a $16 \%$ superior ultimate strain. It was observed that volume fraction of Carbon black is approximately two times the real volume fraction and for functionalized graphene sheet effective volume fraction is 30 to 90 times higher than actual volume fraction. The crystallization of FGSs filled NR started at low level strains compared to the CB loading with NR. In functionalized graphene sheet filled NR systems, the crystallites are toughly oriented by stretching compared to the carbon black filled natural rubber systems. SAXS measurement revealed the FGS sheet orientation and deformation under extension process, which is not observed. Fayong Li et al., ${ }^{7}$ prepared NR composites with fillers graphene and graphene oxide by ultrasonically assisted latex mixing processes. The tensile strength showed improvement due to the addition of dual fillers GE and GO. Graphene has better reinforcing effect compared to the graphene oxide. The SIC in vulcanized natural rubber is the result of GE. Strain induced crystallization process is determined by using synchrotron WAXD. The presence of filler GE induced faster stain induced crystallization rate and greater crystallinity related to the GO filler. The analysis of NR chain network parameter for GE loading NR and GO filled NR composites was carried out by using entanglementtube. The GE/NR composites exhibited low level deformation entropy for the period of stretching compared to the graphene oxide/natural rubber composites.

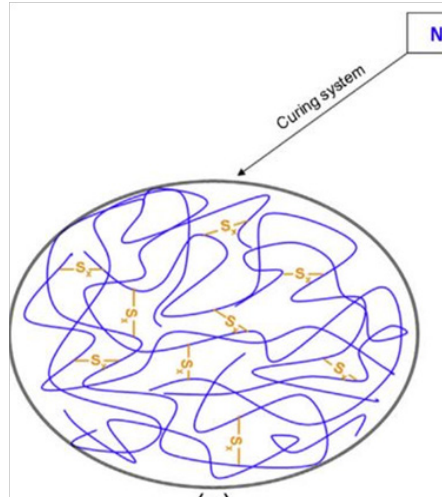

(a)

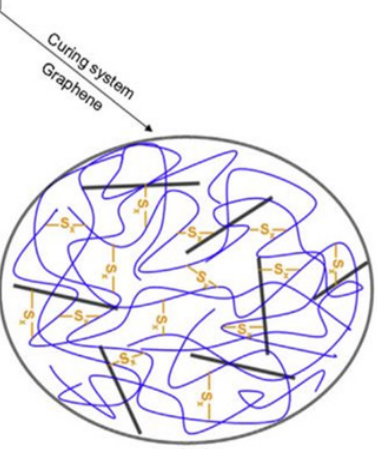

(b)
Figure I Schematic representation of the network structures of $(A)$ neat NR and (B) GE filled NR nanocomposites. ${ }^{5}$

Jeffery R Potts et al., ${ }^{2}$ prepared NR having RGO that showed remarkable improvement in mechanical, electrical, thermal properties. The Properties improvement mainly depended upon the processing history and nanocomposite morphology. The Figure 2 shows fabrication routes for GE based materials from graphite oxide. ${ }^{8}$ The NR composites were prepared by two methods: (i) Two-roll mill and (ii) solution treatment. The two-roll mill mixing up this physical structure, yielding a uniform and enhanced distribution, where as cocoagulation of NR filled with RGO produced a web like morphology technique with platelet networks in the middle of latex. The network morphology process gave more benefit for thermal stability and electrical conductivity properties and dramatically improved stiffness, but then reduced the elongation. The stiffness and strength improved for milled nanocomposites. Muataz Ali Atieh et al., ${ }^{9}$ The radiation vulcanization of NRL with CNTs was done with $150 \mathrm{ev}$ electron beams. The CNTs in the rubber were loaded from $1-7 \mathrm{wt} \%$. The tensile modulus of nanocomposites increased with CNTs content up to $7 \mathrm{wt} \%$. The SMR-L matrix was dispersed homogeneously with CNTs to enhance the mechanical properties of the composites, like hardness, tear strength, tensile strength, break of elongation and tensile modulus. The commercial importance of nanostructured carbon 
materials like buckminsterfullerene, CNTs and carbon nanofibers has greatly improved. The carbon nanotubes show better mechanical and electronic properties. The strongest bond with in nature is carboncarbon covalent bond. Production of CNTs with grater purity was carried out using chemical vapor deposition. CNTs were characterized by using different FESEM and TEM. Nanocomposites were produced by solvent casting method using toluene. Carbon nanotubes were first dissolved in toluene solvent in order to separate the nanotubes. NR was separately dissolved in toluene solution. Finally both the solutions were blended to obtain the composite. The nanocomposites prepared by solvent casting method with toluene as solution had the maximum stress value as $0.56413 \mathrm{MPa}$. The adding of $1 \mathrm{wt} \%$ of carbon nanotubes to irradiated rubber increased stress level of nanocomposites from $0.2839 \mathrm{MPa}$ to $0.56413 \mathrm{MPa}$. Carbon nanotubes of $7 \mathrm{wt} \%$ with NR produced stress value of $1.7 \mathrm{MPa}$ viz6 times that of pure NR. This indicated that by increasing the carbon nanotubes in rubber, the ductility can be decreased with increase in brittleness.

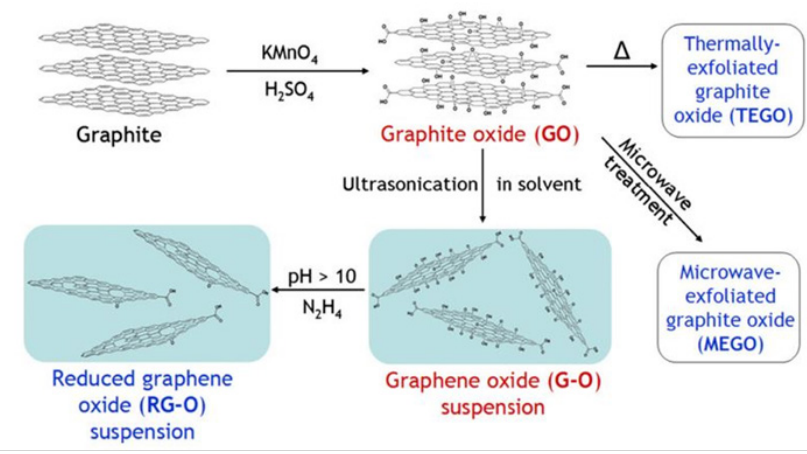

Figure $\mathbf{2}$ Schematic showing production routes for graphene-based materials from graphite oxide (GO). ${ }^{8}$

G Sui et al., ${ }^{10}$ prepared the NR/CNT nanocomposites through the solvent mixing followed by two-roll milling process. Chemical vapour deposition produced CNTs that were pretreated using acid immersion followed by ball milling were added to hydrated silica, resorcinol, and HRH bonding system to reduce curing rate of NR. CNTs pretreated process increased the glass transition temperature for CNTs/NR composites. The good interfacial attachment existed between treated CNTs and rubber matrix. CNTs-reinforcement in NR nanocomposites considerably improved the mechanical properties related to the pure NR and conventional carbon black with natural rubber nanocomposites. The $\mathrm{CB}$ filled NR composites revealed better dynamic compression properties. The addition of treated CNTs to the rubber matrix improved the thermal stability and other properties due to better reinforcement of CNTs. Ali Vahidifar et al., ${ }^{11}$ compression molding technique become planned and effectively applied for making plans of closed-cell foams based totally on characteristics NR loading $\mathrm{CB}$ nanocomposite. The rheometrical discoveries established that the increment inside the $\mathrm{CB}$ substance from to $20 \mathrm{phr}$ produced a 0.91 and $3.51 \mathrm{~N} \mathrm{~m}$ increment inside the beginning and the ultimate torque, in my opinion. Mechanical examine of the natural rubber/carbon black foams exposed that carbon black superior the stiffness, compression modulus and also electricity while it reduced the resilience. This result can be interrelated to the morphological modification in the foam cells and within the natural rubbermedium's mechanical properties with improved carbon black filler content. Lopez-Manchado M et al., ${ }^{12}$ The impact of the embodiment of SWNTs on the mechanical and physical properties of NR were characterized. The Characterization of those new materials become accomplished by using DSC, DMA evaluation, and Raman spectroscopy to achieve evidence approximately the perfect interfaces among materials in addition to the distribution of SWNTs in rubber matrix. The outcomes were then matched with those achieved for natural rubber loading with $\mathrm{CB}$ composites. DMA showed a more filler/rubber matrix interaction in the case of SWNT sand indicated appreciable reduction of the height of $\tan \delta$ peak and a marked shift of $T_{g}$ against better temperatures. In precise, the enhanced of the storage modulus exhibited a valuable effect of SWNT combination with respect to natural rubber filled with carbon black. Calorimetric evaluation displayed that dual fillers enhanced the NR matrix vulcanization reaction, the impact being more apparent while SWNTs have been brought into the rubber matrix. Raman spectroscopy exhibited that SWNT distribution into the natural rubber matrix built residual strain on the nanotubes bundle. It was bring into being that the Raman microprobe method providing a means for load transmission efficiency of SWNTs.

Adedigba A Abdul-Lateef et al., ${ }^{13}$ achieved dispersion of MWCNTs into NR nanocomposites by solution casting technique. In this method CNT were mixed in natural rubber solution and the solvent was dispersed to form the composites. $6 \%, 38 \%$, and $124 \%$ enhanced in the young's modulus of the rubber were attained at $1 \mathrm{Phr}$, $5 \mathrm{Phr}$ and $10 \mathrm{Phr}$ loading of CNT in rubber composites respectively. CNT content increased the toughness of the composites. The glass transition and melting temperature of the composites material also increased incrementally with addition of CNT content. The tensile strength increased by $14.3,314.3$, and $667 \%$ at 1,5 and $10 \mathrm{Phr}$ loading respectively. This phenomena was due to the uniform distribution of stress applied through the matrix. Bokobza $\mathrm{L}^{14}$ found that electrical and mechanical properties of the MWCNTs/NR nanocomposites depended on nanofiller loading. Solution mixing methods had been used for preparing MWCNTs/NR composites. The increasing MWCNTs content in NR decreased the volume resistivity. At less than 1phr loading of MWCNTs, electric percolation threshold was reached. This effect occurred due to the formation of conductive chain in the composites. Lack of increase in rupture properties were due to the presence of a less number of agglomerates. The high aspect ratio (Halpin-Tsai model) of 90 for carbon nanotubes had considerable impact on mechanical reinforcement and electric conduction. Application of an uniaxial deformation increased the electric resistivity of the composites as well as storage modulus dropped when the sample object was subjected to low shear strains. Mohd Shaiful Zaidi Mat Desa et al., ${ }^{15}$ analyzed the impact of poly lactic acid (PLA) into natural rubber modified composites containing carboxylic functionalized MWCNT. PLA/NR/MWCNT nanocomposites were fabricated by straight melt blending in a counter-rotating twin screw extruder with the temperature intermediate between the range of 160 to $190^{\circ} \mathrm{C}$. The mechanical properties like that tensile, flexural and impact test were determined for PLA/NR/MWCNT nanocomposites at different loading in NR. Flexural and tensile properties were measured on Lloyd testing machine at testing speed of 3 and $5 \mathrm{~mm} /$ min separately. V-notched samples with Izod test techniques were used to measure impact strength. Neat PLA, PLA loading with NR composites with $5 \mathrm{wt} \%$ of NR and PLA/MWCNT with $1 \mathrm{phr}$ carbon nanotubes were also fabricate with counter-rotating twin screw extruder. The better overall mechanical properties were indicated at PLA composites with $10 \mathrm{wt} \%$ NR loading and $1 \mathrm{phr}$ carbon nanotubes contents, in which high elongation at brake and impact strength were noticed. H Lorenz et al., ${ }^{16}$ MWCNT dispersed in rubber the usage of an internal mixer have been subjected to testing and physical properties of the composites such as stress-strain behavior, thermal diffusivity, 
dynamic-mechanical, dielectric and fracture mechanical properties were evaluated. The electric powered percolation threshold turned into built to loss by means of the usage of ethanol as dispersion agent and as compared to the dry blending corresponding with elevating optical dispersion agent. In NR the fatigue crack propagation resistance, electrical conductivity and tensile strength have been discovered to be elevating for dry combined CNT silica hybrid structures. The electric conductivity of the hybrid structures is considered to be usually biggest as correlated to the pure $\mathrm{CNT}$ or $\mathrm{CB}$ composites given that larger shear force involvement in hybrid structures.

Franco Cataldo et al. ${ }^{17}$ MWCNT were reinforced in NR based composites as partial replacement of $\mathrm{CB}$. NR compound already containing 50phr of $\mathrm{N} 375 \mathrm{CB}$ was loaded with MWCNTs at four levels of $2.5,5,10$, and $15 \mathrm{phr}$. The MWCNTs loading drastically improved the green Moon viscosity, cured hardness, and module. This phenomena was described by neat hydrodynamic effect according to the Enstein -Guth equation. MWCNTs loaded at 10and $15 \mathrm{phr}$ for composites increased the cure speed. It also increased the modulus $50 \%$ higher than the reference compound. Disadvantages of the NR nanocomposites reinforced with MWCNTs were higher hysteresis and heat generation. Mou ad A tarawneh et al., ${ }^{18}$ Fabricated Thermoplastic elastomers fabricated at high shear rate by mixing thermoplastic and elastomer. Two types of MWCNTs were used in the composites. Dispersion of MWCNTs into thermoplastic natural rubber greatly influenced the properties. Addition of MWCNTs ( $1 \& 2)$ increased the tensile strength by $23 \%$ and $39 \%$ respectively. Addition of MWCNTs 1 enhanced the tensile strength and Young's Modulus. Loading of MWCNTs 2 increased the young's modulus considerably. The laser flash technique was used to evaluate the thermal conductivity, specific heat, thermal diffusivity. Dispersion of MWCNTs into TPNRs matrix resulted in good interfacial adhesion is verified by scanning electron microscope (SEM) images. Shanmugharaj AM et al., ${ }^{19}$ Multiwalled carbon nanotubes surface functionalization was done by acid handling followed by response with functionalsilane, 3 -aminopropyltriethoxysilane. The chemical communication of silane with the oxidized nanotube surface was confirmed through FTIR. EDX analysis also conveyed the existence of silane on the surface of the CNT. XRD results show that the modification in the crystalline stages due to surface functionalization. The functionalized MWCNTs exposed the forming of surface defects due to the establishment of carboxyl groups was confirmed by Raman spectroscopy. XRD investigation shows that the modification in the crystalline phase due to silane functionalization. TGA of the functionalized carbon nanotubes displayed three novel peaks at around $250^{\circ} \mathrm{C}$ and at around $520^{\circ} \mathrm{C}$ express the chemical communication between the silane and carbon nanotubes. It also displayed the developing of $\mathrm{Si}-\mathrm{O}-$ $\mathrm{Si}$ bond in the middle of silane on the carbon nanotubes surface and it became prevailing at above severe concentration. The effect of silane functionalized CNT on the rheometric and mechanical properties of the natural rubber vulcanizates was resolved. NR/ silane functionalized CNTs nanocomposites showed greater modulus, tensile strength and elongation at break. Omar A Al-Hartomy et al., ${ }^{20}$ studied the dispersion of fullerene into natural rubber nanocomposites prepared by using an two-roll mill. Fullerene/NR nanocomposites and vulcanization characteristic of both compounds, physico mechanical, dynamic, and dielectric properties and thermal aging resistance were also investigated. The effect of fullerene dispersion into rubber matrix was also analyzed. The NR-SMR 10 type of neat rubber was filled into two-roll mill and zinc oxide, stearic acids were adding after 5 minutes. Fullerene powder was added after $3 \mathrm{~min}$ homogenization. The accelerator and sulfur were added after $7 \mathrm{~min}$ in another homogenization process and composites compound was rehomogenized for $4 \mathrm{~min}$. The nanocomposites compound was fabricated for $19 \mathrm{~min}$. Vulcanization characterization was measured on vulcanization isotherms occupied on an fluctuating disc vulcameter MDR. Dynamic properties and mechanical loss angle tangent were measured on dynamic mechanical thermal analyser MKIII system (DMTA). Dielectric properties were measured on dielectric thermal analyser (DETA). Shore A hardness was investigated. Thermal aging resistance was determined. The nanocomposites morphology was investigated by scanning electron microscope. Microstructure and size of particle, filler distribution size were also investigated by TEM. The influence of fullerene into NR composites with increased amount of prolongs induction period was studied. The increment in fullerene amount, incremented the values are $\mathrm{M}_{100}$ and $\mathrm{M}_{300}$ and shore hardness while tensile strength decreased. The effect of fullerene into rubber composites led to enhanced the thermal aging resistance. The electric properties such as dielectric permittivity and dielectric loss angle tangent were also examined by DETA.

Predeep P et al., ${ }^{21}$ prepared memory device based on $\mathrm{C}_{60}$ fullerene molecules and natural rubber (cis1, 4polyisoprene). It is construct that NR nanocomposites with a fullerene molecules alike as low as $0.1 \%$ performance bistability and switching behavior. The NR/C nanocomposites displayed electrical bistabilities including an apparent hysteresis, whatever could be associated to the carrier storage in the fullerene $\mathrm{C}_{60}$ content. The bistability magnitude of I-V curves for the organic bistable device (OBDs) based on the $\mathrm{C}_{60}$ content installed in the NR layer increased with improvement in $\mathrm{C}_{60}$ concentration. It was displayed that this hysteresis was used for read-write-erase functions. The thickness of effective intermediate layer and the combination of $\mathrm{C}_{60}$ content affected critically the electrical bistability behavior of the nanocomposites. Ammar E Khadom \& Kutaiba H Mohammed., ${ }^{22}$ used three various carbon allotropes Graphite, CB (N330), and AC with various weight percentage of $10,20,30,40, \& 50 \%$ as reinforcing filler in natural rubber and studied their effects on elastomer properties such as resilience, hardness, moony viscosity, tensile strength, and elongation. The samples were prepared by passing rubber through mill rollers at $70^{\circ} \mathrm{C}$ and then reinforcing particles (N330 or GR or AC) were added along the weight percentage suggested previously. The processing oil, stearic acid, zinc oxide, anti -oxidation, anti ozone were also added. Rheometer was used to investigate the properties while vulcanization processes. Mechanical tests (hardness and resilience) were conducted according to the ASTM-D 2240 (shore A hardness) standard. Tensile strength and elongation test were inspected according to ASTM-D 3182 and D-13192.

Omar A Al-Hartomy et al., ${ }^{23}$ Dispersion of standard furnace carbon black $(\mathrm{CB})$ in constant amount of 50phr and GNP in concentration range from 1 to $5 \mathrm{phr}$ into natural rubber (NR) was achieved by using open two-roll laboratory mill. NR containing CB and GNP composites exhibited dielectric properties like dielectric loss, dielectric permittivity and microwave properties between frequency ranges from 1-12 GHZ. The dielectric and microwave properties were measured by different type of measuring techniques. Low amount of GNP (1-5phr) and constant amount of CB were used as a way to control and enhance the properties of nanocomposites. The second filler GNP was incorporated into NR composites to produce specific absorbing properties. Bin Dong et al., ${ }^{24}$ explored the crack and fatigue resistance of NR loading with zero-dimensional spherical CB, $1 \mathrm{D}$ (one dimensional) fibrous CNTs and 2D(two-dimensional) planar GO. The 
equal hardness level founded in the NR composites loading with $10.7 \mathrm{vol} \%$ carbon black, $1.2 \mathrm{vol} \%$ carbon nanotubes, and $1.6 \mathrm{vol} \%$ grapheme oxide.J-integral and dynamic fatigue tests exposed that, under quasi-static conditions and in dynamic conditions, CB-10.7 shows high level of fracture initiation and propagation resistance and fatigue crack developed resistance.CNTs-1.2 fatigue resistance was weakened because of the much higher hysteresis loss. Digital appearance correlation exposed that NR loading with CB dissipated the most local input energy and provided the maximum strain amplification range at the crack tip and then improved the fracture and fatigue performance

Yonglai Lu et al., ${ }^{25}$ were grafted a film of polyacrylic acid through plasma made polymer grafting on CNT bundles with 1Dalignment arrangement structure. Modified CNTB was mixed into NR matrix through the silane in-situ modification-dispersion method done by mechanical blending technique. Many number of Carboxyl groups dispersed in the surface of CNTB-PAA can be exposed to dealcoholization reaction with silicon hydroxyl $(\mathrm{Si}-\mathrm{OH})$ produced from the hydrolysis of silane joining agent, and an only sulfur bond of Si69. Data from the HR-TEM, XPS and TGA showed that the surface grafting of carbon nanotube bundles was successful. SEM and RPA tests were showed that the improvement of the interfacial attachment between filler and matrix. The nanocomposites had a considerably reduced network effect of fillers materials and an enhanced interfacial attachment between CNTB and rubber matrix. This kind of composite had good dispersion and strong interface, so that the dynamic hysteresis damage and heat built-up was decreased.

Hailan Kang et al. ${ }^{26}$ fabricated graphene/ natural rubber nanocomposites by direct mechanical blending method and the characteristic of graphene was investigated by FTIR, XPS and XRD. Fourier Transform Infrared Spectroscopy used to characterize the chemical variation throughout the method of oxidation and decrease of graphite. The FITR spectra of graphene, graphene oxide and graphite were shown in Figure 3A. A new absorption at $1725 \mathrm{~cm}^{-1}$ of GO will clearly be seen in the graph and it was assigned to $\mathrm{C}=\mathrm{O}$ absorption peak. After the hydrazine hydrate reduction the $\mathrm{C}=\mathrm{O}$ absorption peak of graphene oxide disappears. ${ }^{26}$ Figure $3 \mathrm{~B}$ shows that the survey $\mathrm{X}$-Ray photoelectron spectroscopy of the graphite, GO and GE nanoparticle Samples. The maximum intense peak in the XPS spectra $\sim 284.6 \mathrm{eV}$ was conformed to $\mathrm{sp}^{2}$ and $\mathrm{sp}^{3}$ carbon atoms. ${ }^{26}$ Moreover, the XRD patterns of pristine graphite, GO and GE was shown in Figure 3C. After oxidation, GO illustrations a tough diffraction peak up to $10.9^{\circ}$. The mechanical properties of graphene filled natural rubber nanocomposites were improved by adding of $2 \mathrm{phr}$ graphene and it exhibited greater strength at low content and lower the internal friction then the $\mathrm{CB}$ composites and graphite composites.

Jong Hyuk Cha et al., ${ }^{27}$ fabricated carbon black/NR composites by addition various types of CB fillers (N 220, N330, N550, and N774) to a natural rubber matrix and it were examined by XRD and BrunauerEmmett-Teller isotherms to finding the relationship among the filler material and the rubber matrix, the adsorption and surface properties of the CB samples. The crystallinity and particular surface region were opposite to each other and the specific surface area affected the London dispersive component of the surface free energy. The best mechanical properties exhibited in the $\mathrm{CB} / \mathrm{NR}$ composites containing N220. Complete, the mechanical properties of the $\mathrm{CB} / \mathrm{NR}$ composites were improved when $\mathrm{CB}$ was used as the filler. Giuseppe Scherillo et al., ${ }^{28}$ was proposed a method for obtaining nanocomposites with enhanced gas barrier properties by self-assembling of RGO platelets, as a tailored interrelated network within a NR matrix. The highlights of this graphene-isolated structure have been contrasted as those of rubber/filler nanocomposite where platelets are homogeneously scattered in a not-isolated morphology. Huge subjective and quantitative contrasts in the reliance of the relative penetrability on the volume division of filler have been found for the two morphologies. Tested samples shows a segregated morphology exhibition and a steeper reduction of permeability at low graphene focus. NR/ GE nanocomposites with 3.38 vol \% reduced graphene oxide were prepared by, (a) self-assembly in rubber latex and static hot pressing (b) self -assembly in rubber latex and two-roll mixing mill. (a', $\left.\mathrm{b}^{\prime}\right)$ were the enlarged images of $a$ and $b$. Due to limitation of graphene on the surface of the rubber latex circles the filler presence in sample was more effective in falling the whole permeability.
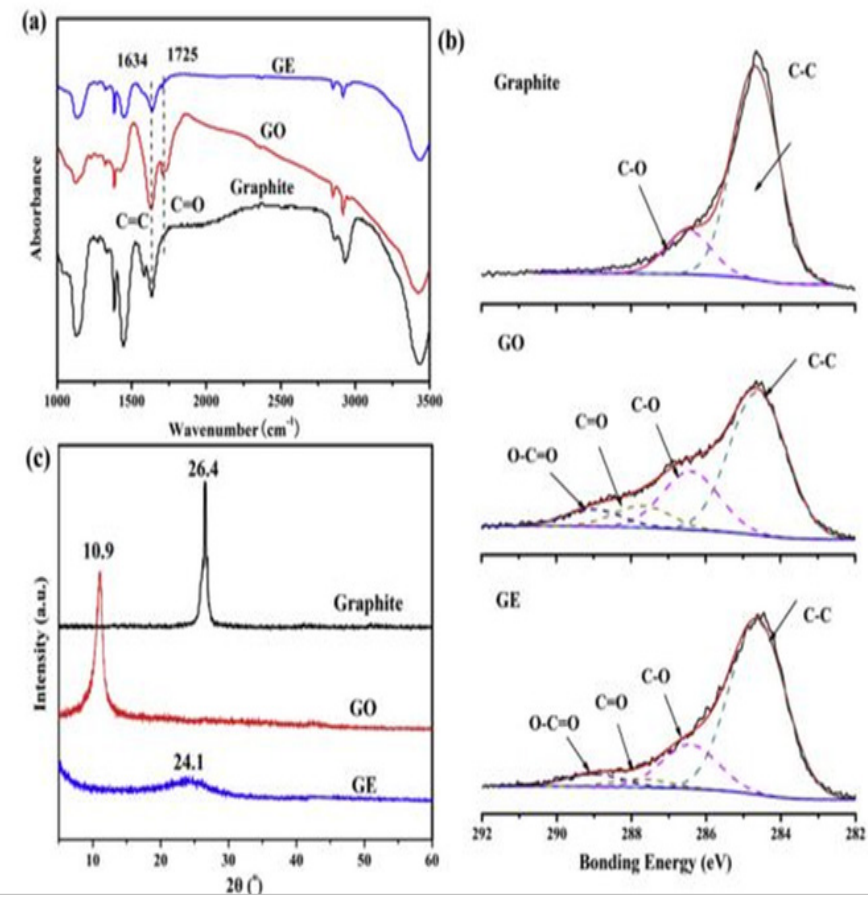

GE

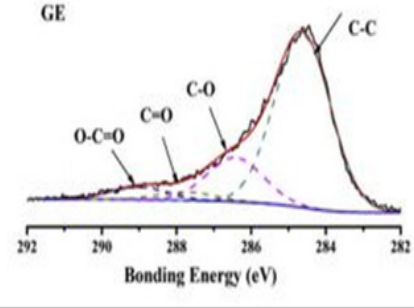

Figure 3 (A) FT-IR spectra of graphite, GO, and GE; (B) XPS spectra of graphite and GO; (C) XRD patterns of graphite, GO, and GE. ${ }^{26}$

\section{Styrene butadiene rubber nanocomposites}

Song $\mathrm{SH}^{29}$ achieved dispersion of reformed graphite and naturalgraphite with concentration level of $5 \mathrm{wt} \%$ into reinforcement with SBR matrix. SBR latex with 5phr natural graphite, reformed graphite, $\mathrm{CB}$ and coupling agent $0.8 \mathrm{phr}$ was prepared. A modified-graphite was prepared by techniques like acid treatment, thermal shock, and sonication. The adding of vulcanization agent sulfur helped to start the solidification processes of the mixer. Sulphuric acid and nitric acid using oxidized graphite platelets were investigated by the Raman Spectra, XRD, and FT-IR. The FT-IR results were evaluated for acid groups in tread samples. The irrespective processing techniques did not change the structure of XRD peaks. SEM investigated the morphology performance of the graphite platelets. The thermal conductivity was measured on thermal conductivity analyzer. The electric resistance was investigated by the two-probe technique. Curing characteristics were measured on rheometer. Shore A hardness was analyzed by durometer. Demmattia was used to measure the fatigue properties. 
Tensile strength of composites was described by using intron tensile machine. The results obtained exhibited that nanocomposites filled with acid-graphite platelets improved mechanical properties. Dynamic properties of composites were not affected by processing techniques.

Amit Das et al., ${ }^{30}$ achieved dispersion of GnP, EG, and MWCNTs through to solving SBR by two-roll mill. Their electrical and mechanical properties were correlated to observe the exact diffusion. The Rubber synthesize was prepared by two stages. In stage 1, rubber was synthesizing with $\mathrm{ZnO}, \mathrm{SA}$, and filler in an inner mixer at rotor speed of $70 \mathrm{rpm}$, temperature range $70^{\circ} \mathrm{C}$. Rubber compound processed for several min was taken outside. In stage 2, rubber compound subjected into the two-roll mill at temperature $40^{\circ} \mathrm{C}$. Rubber compounding was handled for $10 \mathrm{mins}$. In inclusion of single filler method and hybrid filler EG (or) GnPs with MWCNT were planned. The curing time was measured on rubber process investigator. Tensile test was conducted by a Zwick universal testing machine at the speed $200 \mathrm{~mm} / \mathrm{min}$ as per ASTM International norms. The morphological behavior was investigated on transmission electron microscope. The powders of GnPs and EG accumulate on the SBR surface were investigated on SEM by accelerating voltage of $3 \mathrm{KV}$ without further treatment. The mechanical and electrical properties of the two types of composition were investigated. The MWCNT has high aspect ratio. MWCNT enabled the continuous filler network formation at low level filler loading and reinforcement effect was high compared to the GnPs and EG composition. GnPs showed that percolation behavior comparatively at filler loading was lower correlated to the EG. Dispersion of GnPs and EG was not sufficient for composites properties. The hybrid filler adding (ie) narrow amount of MWCNT increased properties of the composites.

Jin Sil Kim et al., ${ }^{31}$ MLGS/ SBR composites by hetrocoagulation process between SBR latex particles and MLGS in completely surface reformed water through the adding of flocculent, and PAC. The composites were fabricated at room temperature. The composite particles size ranged from 10-20 $\mu \mathrm{m}$, Scanning electron microscope morphology revealed that MLGs were fine dispersed into SBR latex below the optimum condition. The TEM was used to investigate the shape of MLGs. The particle analyzer was utilized to determine the size and distribution in SBR matrix. Composites were prepared by heterocoagulation method with $0.5 \mathrm{~mL}, 2.5 \mathrm{~mL}$, and $6.0 \mathrm{~mL}$ PAC solvent. Thermal stability and weight composition were investigated by TGA. Hiresta-UP MCP-HT450 was used to measure the electric conductivity of composites. The thermal stability was slightly increased due to the $\pi-\pi$ intercommunication between the phenyl group of SBR matrix/MLGs. MLGs/SBR composites incremented the electric conductivity from $4.52 \times 10^{-3}$ to $4.56 \times 10^{-7} \mathrm{~s} / \mathrm{cm}$ with as well as increase in the MLGs range from 0.5 to $5 \mathrm{wt} \%$. Stephanie Schopp et al., ${ }^{32}$ obtained dispersion of functionalized graphene into styrene butadiene rubber by using pigment blend techniques. All fillers were dissolved in water. SBR/FG nanocomposites based on TROG and CROG were analyzed. Electron microscopy and X-ray tomography were used to verify the extremely sufficient FG distribution in SBR and the concurrent increment of mechanical behavior, electrical conductivity, and also gas barrier resistance. The achievement of SBR filled with TRGO, SBR loading CRGO, and SBR incorporated multilayer graphene with stacks of fewer than $10 \mathrm{FG}$ sheets, was distant remarkable to multilayer FG incorporate stacks more than $60 \mathrm{FG}$ layers and traditional carbon fillers like that carbon black and carbon nanotubes. At 50\% strain the tensile strength of SBR incorporated with $25 \mathrm{phr}$ filler somewhat incremented for SBR/MLG350 (800\%) and SBR/TRGO (1400\%). The distribution of TRGO incremented gas hurdle resistance joined with enhanced mechanical properties and electric conductivity.

Bulent Ozbas et al., ${ }^{33}$ obtained dispersion of functionalized graphene sheet into three elastomers such as NR, SBR, and PDMS. FGSs or multifunctional nanofillers were added to increase gas permeability, mechanical properties, and electrical conductivity for a number of distinct rubber. FGS consisted mainly of single sheet crumbled GE incorporated oxygen functional groups and was induced by the thermal exfoliation of GO. The presence of FGS in NR matrix was observed using FSEM. The mechanical properties of FGS/SBR and FGS/NR nanocomposites were studied. FGS/SBR and FGS/NR nanocomposites were compared with the traditional carbon black. Sixteen times higher amount conventional CB fillers were needed to reach the same stiffness as FGS. The reduced gas permeability was due to the maximum aspect ratio of FGS. FGS/PDMS nanocomposites showed dramatically improved electric conductivity at FGS loading as low as $0.08 \%$. Tahar Laoui et al., ${ }^{34}$ studied the effect of reinforcing SBR withF-CNTs on the thermal and mechanical properties of the nanocomposites. MWCNTs were functionalized including phenol functional group to improve their dispersion in styrene butadiene rubber matrix. Fewer amounts of filler loading extensively enhanced the mechanical properties of the virgin SBR. Including of $10 \mathrm{wt} \%$ CNTs-Phenol into SBR matrix enhanced tensile strength from $0.17 \mathrm{MPa}$ to $0.48 \mathrm{MPa}$ and at the same time Young's Modulus enhanced from $0.25 \mathrm{MPa}$ to $0.83 \mathrm{MPa}$. The energy absorption also enhanced $4.1 \mathrm{KJ}$ with the loading of $1 \mathrm{wt} \%$ CNTs-phenol through the SBR matrix. The Fourier Transform Infrared Spectroscopy and TGA test data established the existence of the Phenol functional group, added onto the surface of CNTs, and its comparable degeneration enhanced the temperature in the inert atmosphere. From the investigation, it was found that CNTs functionalized with phenol group, granted a good dispersion and can be treated as exceptional nanofiller for SBR matrix. Xiang-Wen Zhou et al., ${ }^{35}$ obtained dispersion of CNTs and CB loaded powder in SBR matrix latex by spray drying. The powder compositas; were sphere like and exceptional with equal diameter of 10 to $15^{\mu}$ m.Empirical result exhibited that the launch of CNTs into the matrix was valuable to enhance the surveillance vulcanization of the elastomer composites and the dynamic and primary mechanical properties of the CNTs/SBR nanocomposites were improved than those of $\mathrm{CB} / \mathrm{SBR}$ and Pure SBR composites. The dynamic mechanical investigation exposed the reinforcement reaction of CNTs on SBR matrix. In case, the embodiment of CNTs with SBR provided increase to a more rigid material, with remarkable raise in the storage modulus. The fracture investigation of the tested specimen indicated that the Carbon nanotubes were fully dispersed in the composites and had a better interfacial bonding with the SBR rubber matrix.

Koji Tsuchiya et al., ${ }^{36}$ obtained a better dispersion of CNTs into styrene-butadiene rubber, which led to rise an electrical properties. The two different types of mixing methods used were: (1) rotation - revolution mixer (2) Banbury mixer. In this work, CNT/SBR was fabricated by a rotation-revolution mixer at novel mixing approach. The conductive behaviour of the composites fabricated by the current method was related with the CNT/SBR composites fabricated with a Banbury mixer. The Rotation -revolution result obtained indicated significantly decrement percolation threshold of CNTs/SBR at less than $1 \mathrm{phr}$ loading. Mixing method consists of (i) pre-treatment processes by sonication to disentangle the bundles of CNT in organic solution and. (2) rotation-revolution mixing techniques. In this mixing 
method, dispersion agent was not added. Dielectric conductivity $(10 \mathrm{KHz}-100 \mathrm{KHz})$ was used to measure the AC electric conductivity of composites. Impedance analyzer 4192A LF was investigated to cover a broad frequency range. The morphological behavior and dispersion of CNTs into SBR were analysed by TEM. The obtained indicated that Rotation -revolution method can decrease the less amount of CNTs necessary to produce high electric conductivity of the SBR. Nazlia Girun et al., ${ }^{37}$ A floating catalyst -CVD technique was planned and used to produce excellent CNTs. In this work, dispersion of $1-10 \mathrm{wt} \%$ of MW CNTs into SBR was studied. The composites were fabricated by containing CNT in a polymer solvent and evaporating it subsequently. Their properties such as hardness, tensile modulus, tensile strength, and elongation at break were investigated. The morphological behaviour of CNTs were examined by SEM and TEM. SEM of CNTs, exhibited high purity and tens of microns length with uniform diameter. The HRTEM observation showed that these CNTs were highly ordered crystalline structure. Using various percentages of CNTs from $1 \mathrm{wt} \%$ to $10 \mathrm{wt} \%$, the prepared a number of nanocomposites samples were fabricated. The tensile strength was improved from $21.0 \%$ at $1 \mathrm{wt} \%$ of carbon nanotubes to $70.26 \%$ at $10 \mathrm{wt} \%$ carbon nanotubes loading. The Young's Modulus improved from $11.36 \%$ at $1 \mathrm{wt} \%$ of carbon nanotubes to $193.91 \%$ at $10 \mathrm{wt} \%$ carbon nanotubes to loading compared to the neat SBR.

Pedroni LG et al., ${ }^{38}$ achieved dispersion of multiwalled carbon nanotubes into SBR block copolymer by melt mixing method and casting method. The electric conductivity was measured on Coleman's method; Dynamic mechanical analysis and stress-strain test were used to measure the mechanical properties; the thermal conductivity was measured on thermogravimetry, and morphological behavior was investigated by scanning electron microscope. Finally the result of MWCNT/SBS composites was compared to those equipped by the solution casting method. The electrical properties of the composites fabricated by casting were higher compared to the composites fabricated by melt mixing. A concentration of CNT was necessary in the melt mixing composites to obtain conductivity between $10^{-4}$ and $10^{-3} \mathrm{~S} \mathrm{~cm}^{-1}$. The storage modulus change only occurred in composite prepared by casting method as investigated by dynamic mechanical test. The better matrix-filler adhesion in nanocomposite prepared by melt mixing method was examined by SEM images. The two different fabricated techniques presented advantages and disadvantages: the melt mixing process resulted in materials with better mechanical properties and on a large scale, while the casting techniques induced materials with high electrical conductivity and on a small scale. Xinlei Yan et al., ${ }^{39}$ studied the laser heating impact on MWCNTs in SBR/MWCNT nanocomposites by Raman spectra. The intensity ratio of the $\mathrm{I}_{\mathrm{D}}$ to $\mathrm{I}_{\mathrm{G}}$ of SBR/MWCNTs nanocomposites widely reduced by temperature. The rearranging capability of MWCNTs in the SBR/MWCNTs composites improved with temperature. The laser powder was raised, the $I_{D} / I_{G}$ ratios of the MWCNTs in the SBR/MWCNTs composites displayed a quick loss in the initial stage, the intensity of the $\mathrm{I}_{\mathrm{G}}$ became heavy than that of the $I_{D}$ The result for the nanocomposites showed that the degree of disorder in the MWCNTs in the SBR/MWCNTs system decreased considerably. The $\mathrm{I}_{\mathrm{G}}$ of the SBR/MWCNTs nanocomposites indicated a lesser downward trend with temperature raise. When laser light power was raised, MWCNTs in the SBR/MWCNTs systems went through rearrangement; the increased arrangement reduces the amount of impurities or degree of disorder. Das et al., ${ }^{40}$ obtained novel mixing of the carbon nanotubes (CNTs) into a 50:50 mixing of solution SBR and BR. The initial step CNTs were pre-discharged in
$\mathrm{C}_{2} \mathrm{H}_{5} \mathrm{OH}$ and after that the CNT-alcohol interruption was mixed the elastomer composite at raised temperature. The prepared elastomer nanocomposites showed significantly improved physical properties at fewer amount of nanotube concentration. The mechanical properties of MWCNTs loaded S-SBR/BR enhanced appreciably compared to the unloaded rubber. The electrical conductivity analysis exposed the existence of a percolation network at fewer amounts of filler loadings with less quantity of $2 \mathrm{phr}$. In comparison, the percolation threshold for CNT-elastomer composites achieved from classical dry mixing was at $7.5 \mathrm{phr}$. The adding of CNT into the elastomer compound resulted only in a slight improvement of the thermal conductivity compared to the unfilled rubber compound. A modification of CNTs by hydroxyl groups did not enhance the material properties of the resultant composites. A reason was the inadequate number of imported chemical groups of such modified tubes.

Peddini K et al., ${ }^{41}$ prepared surface reformed MWCNT-SBR master batches with up to $15 \mathrm{wt} . \%$ MWCNTs by using coagulation method followed by melt mastication in a laboratory scale. By the investigation of the rheological information and Guthe-Golde-Smallwood theory, effective tube aspect ratios for the nanocomposites with different MWCNT loadings were predictable for uncured samples and the dynamic mechanical properties of cured composites respectively. MWCNTs in the original master batch hold many closely packed and overlapping curved tubes which changes into separated tubes with dilution was confirmed by using STEM images. The transition from overlapping to non-overlapping and straighter tubes was in the range of 4 wt.\% MWCNT loading. Electrical conductivity of these material provided low level from a percolation concept also the material showed representing superior tube dispersion and development of a bound elastomer layer on the separate MWCNT. From the results it shows that the consumption of the tube aspect proportion from simple thoughts of their contour length and diameter were insufficient to predict their rheological and mechanical analysis. Peddini SK et al., ${ }^{42}$ investigated cured SBR nanocomposites enclosing discreet MWCNT absorptions up to $12 \%$ by weight to found the influence of tensile strains (up to value 6). The MWCNTs/SBR nanocomposites were fabricated from a coagulation method and melt mixing in a maximum shear twin screw extruder. Because of the joined reinforcing effect of tubes on SBR and overlay of curved MWCNT the plot results from the Mooneye-Rivlin shows a dramatically change in mechanical performance for the MWCNTs loading exceeded about 5 wt. \%. Mechanical hysteresis and swelling in toluene solvent on cured composites specimens showed that multi walled carbon nanotubes are fine attached to the SBR matrix. Compared with pure SBR, the adding of $\mathrm{CB}$ causes approx. $60 \%$ enhancement in tear energy but while addition of both $\mathrm{CB}$ and MWCNT causes a 2.8-fold growth. It shows that the multi walled carbon nanotubes performance as effective crack bridging components. Costa $\mathrm{P}$ et al. ${ }^{43}$ studied morphological, thermal, mechanical and electrical analysis of SBS/CNT composites with various filler contents and filler functionalization. For this four types of commercial thermoplastic rubber (SBs matrix Calprene C401, C411, C500 and C540) were used with MWCNT-C150P, MWCNT-NC7000, SW CNT-AP-SWNT. The different mixing level of CNT in the SBS matrix was succeeded for perfect and functionalized CNT possessed strong influence in the electrical properties of the nanocomposites. Percolation thresholds higher than 8 weight percentage $(\mathrm{wt} \%)$ showed by Covalently functionalized CNTs and pristine CNT displays that the percolation threshold was lesser than $1 \mathrm{wt} \%$. The typical stress-strain curves of thermoplastic rubber showed that the extreme deformation 
of CNT/ SBS composites were bigger than $400 \%$ and yield strain around 3\%. Electro-mechanical performance of CNT filled with SBS composites have like behavior before and after yielding.

Kumarjyoti Roy et al. ${ }^{44}$ delivered a route on the fabrication of sol-gel derived nano- $\mathrm{TiO}_{2}$-based SBR composites. The outer surface of nano- $\mathrm{TiO}_{2}$ was reformed by cationic surfactants like cetyltrimethylammonium bromide and Tetraethylammonium bromide. FTIR and FESEM were used to illustrate the outer surface modification of nano- $\mathrm{TiO}_{2}$. When compared to the unmodified nano$\mathrm{TiO}_{2}$ Surface-modified nano- $\mathrm{TiO}_{2}$ enhanced the structural physical and thermal properties of SBR composites in maximum level because of the interfacial communication of surface-modified nano- $\mathrm{TiO}_{2}$ with SBR matrix were additional effective than unmodified nano- $\mathrm{TiO}_{2}$ CTAB surfactant was more effective surface modifier than TEAB for $\mathrm{TiO}_{2}$ nanoparticles due to the accurate chain length of nonpolar hydrocarbon moiety. Maryam Hadizadeh Harandi et al., ${ }^{45}$ fabricated BR/NC nanocomposites (SBR 1502) using two-roll mill technique. The thickness and the styrene gratified of SBR were $0.98 \mathrm{~g} / \mathrm{cm}^{3}$ and $23 \%$, separately. The curing performance of nanocomposite specimens were calculated by swelling and cure rheometric experiments. TGA and tensile test were employed to investigate the thermal performance of the SBR matrix and the mechanical ability of nanoparticles. Shear viscosity of SBR matrix was improved with raising the $\mathrm{NC}$ content and it reduced with enhanced the shear rate was founded in rheological measurements. The thermal strength of SBR matrix was reduced by adding of NC. The results showed improved in tensile properties, shear viscosity and curing time of SBR nanocomposites when inclusion of NC filled with SBR matrix. Salimi A et al. ${ }^{46}$ carried out a comparative investigation on distribution of multiwalled CNTs in SBR latex was carried out by using dual anionic surfactants, SLES and sodium dodecyl benzene sulfonate. The two main features affecting the MWNT distribution were the content and the structure of each surfactant. Primarily the MWNTs were pre dispersed in distilled water using two surfactants individually and the pre dispersion MWNT was mixed gently into SBR latex. Using UV spectroscopy the parameters like surfactant concentration, MWNTs functionality, and ultra-sonication time on MWNT distribution in aqueous media were found. The existing $\mathrm{OH}$ group in the multi walled carbon nanotubes in adding to the benzene ring of SDBS surfactant produces a better degree of distribution and stability for the MWNT$\mathrm{OH}$ distribution. By using electrical volume conductivity, microscopy method, and rheological measurements the distribution of MWNTs was described. MWNT functionality exhibited the greater effect of the storage modulus at the terminal zone than the MWNTs content in reaching a good degree of distribution revealed in the rheological measurements of the lattices. At 1phr of MWNT, the percolation threshold of functionalized MWNTs was acquired in conductivity tests, showing the possible formation of an electrical network.

Sima Ahmadi Shooli \& Mitra Tavakolii ${ }^{47}$ were prepared Nanocomposite vulcanizates based on a SBR/ENR50 rubber blend containing nanoclay (5 or 10phr) with and without carbon black (CB 20phr) by melt blending in an internal mixer. Microstructure of nanocomposite samples was investigated by using X-ray diffraction; melt rheomechanical spectroscopy, and scanning electron microscopy. The compound containing $35 \mathrm{phr}$ carbon black (only) was prepared as a reference sample. The XRD patterns revealed that the distance between the clay layers were increased by adding $\mathrm{CB}$ to the nanocomposite samples; they caused better diffusion of chains between the layers and resulted in an intercalated structure. SEM images of fracture surfaces showed the presence of much roughness in the samples containing both nanoclay and $\mathrm{CB}$ compared to the other samples. The sample containing 10phr nanoclay and $20 \mathrm{phr}$ $\mathrm{CB}$ had an increased dynamic elastic modulus, reduced maximum loss factor $(\tan \delta)_{\max }$, and an improved tensile strength and abrasion resistance compared to the reference sample. Also, this sample showed the lowest maximum loss factor, at $50-60^{\circ} \mathrm{C}$, so it can be a candidate for tire-tread application. Liliane Bokobza ${ }^{48}$ achieved nanostructured components of great consequence in the previous decade to explain their broad range of possible applications in many fields. A massive significance was concerned to carbon nanotubes with extraordinary mechanical and electrical properties. The inherent possibility of CNT reinforcing filler in elastomeric component was established. It was displayed that, although a low dispersion, lower amount of filler charging increased the mechanical and electrical performances of the flexible rubber matrix. With the adding of phr of MWCNT into SBR, modulus increased $45 \%$ and a $70 \%$ raise in the tensile length was reached. Straining reaction inspected by AFM and Raman spectroscopes', produced impressive outcomes of the mechanical performance of these nanotube-based composites. The morphology and state of distribution of the CNT in a rubber matrix was inspected using TEM and AFM. All the empirical data led to the interesting fact that the direction of the nanotubes had extensive effect on the mechanical reinforcing process. The heavy constraint in uniformity swelling in toluene solution including MWCNT material was attributed to rubber matrix-filler interfacial communication. CNTimparted conductivity to the insulator rubber matrix.

\section{Ethylene propylene diene monomer rubber nanocomposites}

Biyan Chen et al., ${ }^{49} \mathrm{GO} / \mathrm{EPDM} / \mathrm{PR}$ composites were fabricated by solvent mixing and two-roll mill. SEM was used to measure the dispersion of homogeneous GO nanosheets into EPDM rubber and EPDM/PR blends. The morphology of the chemically modified grapheme oxide nanosheets was investigated by transmission electron microscope and Atomic force microscope. Modified hummer method was used to prepare the GO from flake graphite. Tensile test was examined by SANS-power test V3.0 at $23^{\circ} \mathrm{C}$ at a cross head speed of $500 \mathrm{~mm} / \mathrm{min}$. DMA was analyzed by Q800 dynamic measure instrument. Contact angle test was analyzed by surface energy and low level of interfacial energy of EPDM and GO. The loaded $0.5 \mathrm{wt} \% \mathrm{GO}$ nanosheets improved the tensile strength, tensile modulus, and elongation at break of EPDM by more than $50 \%, 130 \%$, and $30 \%$ correspondingly. The damping properties of EPDM /PR nanocomposites improved with adding of low level of GO nanosheets. The TGA test result indicated slight change in the thermal stability of EPDM /PR composites by GO. Ahmad Allahbakhsh et al., ${ }^{50}$ fabricated the EPDM and GO through the solvent mixing followed by two-roll mill. The cure kinetics of EPDM/GO nanocomposites was investigated utilizing various empirical methods. The response of GO on physical properties of nanocomposites during the curing process was investigated using XRD, SEM, and FTIR. In the existence of $1 \mathrm{phr}$ $\mathrm{GO}$, the activation energy of the autocatalytic cure kinetics raised to about $17 \mathrm{KJ} / \mathrm{mol}$ compared to pure EPDM. This raise was relevant to the increment in stiffness of considered nanocomposites. However, needed energies displayed $75 \mathrm{KJ} / \mathrm{mol}$ reductions pursue by developing the dispersion character of nanosheets within polymer matrix, due to increase of heat transfer. The effective reaction mechanism of cure action was nth-order reaction in order of 2.5 and then the Isayev and Deng experimental model was more adaptable with EPDM/GO 
composites curing system. The impact of GO on crosslink density of nanocomposites was analysed using swelling method and it was exposed that the crosslink density raised up to $11 \%$ with 1 and $3 \mathrm{phr}$ GO loading. This performance was possibly associated to higher degree of communication among GO and elastomer surface during the cure method.

Dubey KA et al., ${ }^{51}$ achieved dispersion of MWCNT into PCR/ EPDM composites by primarily mixing the two rubber components in a brabender plasticorder. Synergistic effect of MWCNT presence as reinforcement and high energy radiation produced cross linking on the thermal and physico-chemical characteristics of PCR/EPDM/ MWCNT rubber nanocomposites. The INSTRON universal testing machine was used to measure the tensile strength and elongation of break. Hardness was determined using durometer. Thermograms of sample were investigated by thermal analyzer. Glass transition temperature was analyzed by DSC. The containing of MWCNT resulted in higher hardness and density. The experimentally analyzed modulus value referred by Halpin-Kardos model indicated the agglomeration of MWCNTs in the rubber matrix. The Kraus plot result indicated high reinforcement of PCR/EPDM 50:50 composite blends with MWCNTs. TGA result obtained indicated the enhancement in thermal stability of composites. The MWCNT content improved the elastic modulus with the radiation. Radiation produced crosslinking between elastomers and MWCNT interface. Jin et al., ${ }^{52}$ fabricatedEPDM/fullerene (C60)nanocomposite, moderately cross-linked by ultraviolet (UV) radiation, to describe the thermal behavior, mechanical properties and crosslink density. FT-IR investigation showed that peak disappearance at $1688 \mathrm{~cm}^{-1}$, related to the unsaturation of EPDM, and the arrival of new peaks related to the forming of oxidation products of fullerene, such as keto, epoxide, carboxylic groups, and aldehyde. Solubility investigation established the dissolution of EPDM in toluene solution even after a lengthy period of UV hazard, because $\mathrm{EPDM} / \mathrm{C}_{60}$ nanocomposite became insoluble and/or swollen after 6hr of UV hazard, displaying the formation of partial crosslinking between EPDM and C60. DSC analysis exposed an enhancement in the glass transition temperature peak of ultraviolet-cured EPDM. TGA displayed that ultraviolet hazard decreased the thermal disintegration temperature of EPDM/C nanocomposites, pristine EPDM and dicumyl peroxide cured EPDM. The tensile strength, modulus, and elongation at break of EPDM/ fullerene nanocomposites were extremely subjective by the period of UV irradiation.

Nabil $\mathrm{H}$ et al., ${ }^{53}$ examined and compared the roles of various vulcanizing methods on the mechanical properties, curing process, morphology and also dynamic mechanical properties of NR and recycled EPDM composites. Speeded up sulfur vulcanizing systems, peroxide, and blends sulfur/peroxide vulcanizing systems were noticed experimental and the composite were prepared on a tworoll mil. Speeded up sulfur vulcanizing process revealed better curing performance and mechanical properties on the other hand the maximum cross-linking density, storage modulus, and hardness were developed in the combinations having a peroxide vulcanizing method. Moreover, the blend sulfur/peroxide- vulcanizing methods exhibited in-between trends in compared with the either sulfur and peroxidevulcanizing methods. The maximum crosslink density detected from the swelling reading can be verified from the storage modulus where peroxide vulcanized mixtures. The Tg of elastomer vulcanizates can be enhanced due to the constraint of molecular motion like that crosslink density.

\section{Butyl Rubber Nanocomposites}

Amin $\mathrm{M}$ et al. ${ }^{54}$ fabricated Composites samples of butyl rubber (IIR)/graphite powder using two various methods in bulk and membrane forms. Their dielectric properties were investigated in the frequency range $10^{2}-2 \times 10^{5} \mathrm{~Hz}$. Dispersion of graphite powder into IIR was done by two-roll mill. The dielectric properties were investigated using a bridge (type GM Instek LCR -821 meter) at the frequency range from $10^{2}-10^{5} \mathrm{~Hz}$. Capacitance and $\tan ^{\delta}$ values were determined for two samples at various temperatures and frequencies. The dielectric constant for both samples was determined by using the equation:

$$
\varepsilon^{\prime}=\frac{\mathrm{d}}{\mathrm{a}_{0} \mathrm{~A}} c
$$

Where,

$$
\mathrm{å}^{\prime}=\text { dielectric constant }
$$

$\stackrel{\circ}{a}_{0}=$ Permittivity of free space

$\mathrm{d}={ }^{=}$thickness of the sample

$\mathrm{A}=$ cross-sectional area of each of the co-ordinate apparent of the sample

\section{$\mathrm{C}=$ capacitance of the sample}

The performance of dielectric constant and the AC electricity can be characterized by the well-done percolation theory. The percolation threshold for two types of pattern was found to be around 0.25 . A variation in the amount of the percolation defender from the global amount was found. Adopting graphite powder as a reinforcing organize filler in IIR matrix element improvement the dielectric constant less magnitude. Sadasivuni Kishor Kumar ${ }^{55}$ IIR/RGO/EG composite have been used present electronics compounds and electrical power devices. The graphene oxide as prepared from graphite flakes by grapher synthesis. Dielectric measurement as concluded using pattern of $\sim$ $0.200 \mathrm{~mm}$ depth using ALPHA kit in the frequency range $10^{1}$ to $10^{7} \mathrm{~F} /$ $\mathrm{Hz}$, against temperature range from -100 to $100^{\circ} \mathrm{C}$. The diffraction as investigated by Philips X-ray diffractometer. The SEM was used to analyse the nanocomposites morphology behavior. The dielectric permittivity improved for reduced grapheme oxide correlated to EG filled composites at $5 \mathrm{wt} \%$ filling although less dielectric loss due to reduced polarization occurred. The piezo resistance of reduced grapheme oxide and Expended Graphite full elastomer blend lower than uniaxial pressure was analyzed. The surface of reduce grapheme oxide sheets increased communication of filler/rubber. Scanning electron microscope and XRD statistics provided information on the dispersion of RGO and EG in IIR. High-achievement elastomer nanocomposites with increased mechanical, sensing and barrier properties were developed by spreading RGO nanosheets in IIR matrix through solution mixing method. The thickness of layer, correlation and reinforcement filler affected pressure sensing.

\section{Nitrile-butadiene rubber nanocomposites}

Jian Yang et al., ${ }^{56}$ followed the effortless latex approach to make finely integrated graphite nanosheets elastomeric polymer composites with enhanced the mechanical performance and functional properties. Graphite nanosheets were realized by thermal composition of graphite and consecutive irradiation of ultrasonic. At the same time, graphite were straight blended with NBRcomposite prepared by using Haake 
mixer. SEM,TEM and XRD analysis displayed that the nanostructure of the finishing composites showed a maximum degree of exfoliation and intercalation of filler graphite nanosheets in the NBR matrix. The SEM images as shown in Figure 4.Mechanical behavior and dynamic mechanical analysis indicated that the graphite nanosheets/ NBR composites carried great improvement in modulus value, tensile strength, and appropriately tough interface. ${ }^{56}$ The unpredictable self-crosslinking of NBR/graphite nanosheets nanocomposites was exposed and then observed by oscillating disc rheometry and swelling analysis also investigated. Appropriate fine distribution of graphite nanosheets induced reactions with elastomer. The NBR/EG nanocomposites carried extremely high modulus and wear resistance, increased tensile strength, exceptional gas barrier performance and good thermal/electrical conductivity. These practical properties made the elastomer/graphite composites a bright novel class of leading material. Pattana Kueseng et al.,57 fabricated NR/ NBR (50/50) composites with MWCNTs by blending on a two-roll mill. The impact of milling direction, TD, and MD on the mechanical properties and electrical behavior of the mixing composite was analysed. The shows specimen preparation for inspecting the effect of milling directions (A) milling direction and (B) transverse direction. ${ }^{57}$ The dichroic ratio achieved from Raman conclusion was excellent and significant witness to express level of MWCNTs alignment. Storage modulus at $30^{\circ} \mathrm{C}$, tensile strength properties and electrical conductivity behavior in TD and MD were extreme when $4 \mathrm{phr}$ MWCNT was loaded, comparable to the maximum dichroic ratio. When MWCNT content was higher than $4 \mathrm{phr}$, the raise of MWCNT agglomerates and devaluation of dichroic ratio were recognized. This led to the devaluation of mechanical properties while the electrical conductivity was constant At $4 \mathrm{phr}$ loading of MWCNTs, $100 \%$ high modulus value and tensile strength in the machining direction obtained were around 1.5 and 1.3 times greater than those in the transverse direction correspondingly. Furthermore, electrical conductivity in the machining direction was remarkable to that in the transverse direction by around 3 orders magnitude. Result against dynamic mechanical tests also displayed that ultimate $\tan ^{\delta}$ in the machining direction specimen was lower than that in the comparable TD specimen.
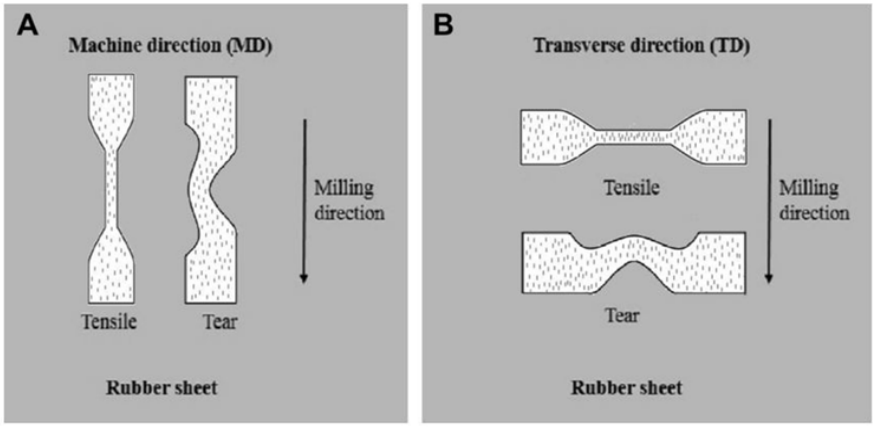

Figure 4 SEM images (A) EG powder pretreated by ultrasonic irradiation (B) NBR composite with 5 phr EG prepared through direct blending. ${ }^{56}$

Leilei Wang et al. ${ }^{58}$ achieved dispersion of expanded graphite into acrylonitrile-butadiene rubber by latex compounding technique used to fabricated NBR loading with EG nanocomposites $\sim$ mpounds with a structure thickness of composite around 20 layers ( $\sim \mathrm{nm}$ size). The dispersion growth of the $\mathrm{EG}$ as consecutive blending and vulcanization was correctly analyzed by using elastomerinvestigation process, TEM, XRD. The exfoliation and maximum aspect ratio of graphite, displayed powerful network at less amount of graphite contents (less than 5phr). At the same time, consecutive blending and vulcanization, pressure, temperature, and shear had considerable influence on the aggregation of excellently dispersed EG. Principally, at the EG content of $5 \mathrm{Phr}$ the basic rigid filler network was unsteady and definitely damaged by shear, resulting in a weakening of dispersion. The early fine dispersion of graphite content was controlled by reduction the shear during blending, pressure, and curing at maximum temperature, and reinforcement the interaction in the middle of the EG and NBR. ${ }^{59}$ Asish Malas and Chapal Kumar Das explored the synergistic effect of expanded graphite/carbon black and reformed graphite/carbon black on the physical behavior, mechanical performance, dynamic mechanical analysis, thermal/electrical conductivity, and gas barrier properties of IIR vulcanizates. The modifications achieved in the morphology, curing performance, mechanical properties, dynamic mechanical analysis, thermal and barrier properties of the elastomer nanocomposites have been studied. EG and modified EG flakes loaded IIR matrix composites were prepared by direct blending on an open two roll mill. Huge surface area of the twin fillers promotes the curing performance in the elastomer nanocomposites that provided a reduction of scorch time and cure time. The occurrence of different functional groups on the surface of MEG is confirmed by FTIR investigation and significant enhanced in the d-spacing of modified expanded graphite was detected from the WAXD. The WAXD pattern of MEG filled rubber composites exhibited incomplete exfoliation of modified expanded graphite sheets in the rubber matrix. Improved dispersion of modified expanded graphite in the IIR matrix in the occurrence and lack of $\mathrm{CB}$, modified expanded inclusion rubber vulcanizates show higher gas barrier, mechanical, and dynamic mechanical properties among the another composites. Yinhang Zhang \& Ur Ryong $\mathrm{Cho}^{60}$ were fabricated NBR /GO and NBR / MGO nanocomposites by latex compounding method. GO is chemically reformed with MPTMS and slightly reduced by one-pot treatment, instantaneously. The GO exfoliation, reformed $\mathrm{GO}$, and the distribution of GO sheets in rubber matrix were investigated using WAXD, FTIR, and TEM. The FT-IR and morphology investigation of uncured rubber composites confirm the reduction process. The mechanical performance of pristine NBR loading with GO and NBR filled with MGO nanocomposites were analyzed within a filler range between $0-2 \mathrm{phr}$. The NBR filled with MGO nanocomposites are providing with higher dynamic mechanical performance and mechanical properties related with the NBR loading GO nanocomposites at the same filler loading.

\section{Conclusion}

Rubber blends are extensively used in various applications along with specialty elastomer blends depending on service demands and component requirements. It can be seen that $\mathrm{CB}$ is the maximum used reinforcing filler in spite of its limitations. The primary properties of carbon black depend on the particle size, surface area and surface activity. The same properties of rubber compounds can be obtained by adding very small quantities of carbon based nanofillers like graphite, graphene, graphene oxide, carbon nanotubes (CNTs), fullerene etc. These nanofillers have definite potential as reinforcements in rubber / elastomer nanocomposites.

\section{Acknowledgments}

None.

\section{Conflicts of interest}

Authors declare that there is no conflict of interest. 


\section{References}

1. Pott JR, Om S, Murali S, et al. Latex and two-roll mill processing of thermally-exfoliated graphite oxide/natural rubber nanocomposites. Compos Sci Technol. 2013;74:166-172.

2. Malas A, Dasa CK, Das A, et al. Development of expanded graphite filled natural rubber vulcanizates in presence and absence of carbon black: Mechanical, thermal and morphological properties. Mater Des. 2012;39:410-417.

3. Hernandez M, Bernal Maria DM, Verdejo R, et al. Overall performance of natural rubber/graphene nanocomposites. Compos A Sci. Technol. 2012;73:40-46.

4. Al-Hartomy OA, Ghamdi AA, Dishovsky N, et al. Mater Sci Appl. 2012;3:453-459.

5. Wu J, Xing W, Huang G, et al. Vulcanization kinetics of graphene/natural rubber nanocomposites. Polymer. 2013;54(13):3314-3323.

6. Ozbas B, Toki S, Hsiao SS, et al. J Polym Sci B Polym Phys.2012;50:718723.

7. Li F, Yan N, Zhan Y, et al. Probing the reinforcing mechanism of graphene and graphene oxide in natural rubber. J Appl Polym Sci. 2013;129:23422351 .

8. Pott JR, Om S, Murali S, et al. Processing-Morphology-Property Relationships and Composite Theory Analysis of Reduced Graphene Oxide/Natural Rubber Nanocomposites. Macromolecules. 2012;45:6045-6055

9. Atieh MA, Girun N, Ahmadun FR, et al. A ZoNano.2005;1:1-11.

10. Suil G, Zhong WH, Yang XP, et al. Preparation and properties of natural rubber composites reinforced with pretreated carbon nanotubes. Polym Adv Technol. 2008;19:1543-1549.

11. Vahidifar A, Khorasani SN, Park CB, et al. Fabrication and Characterization of Closed-Cell Rubber Foams Based on Natural Rubber/Carbon Black by One-Step Foam Processing. Ind Eng Chem Res. 2016;55:2407-2416.

12. Lopez-Manchado MA, Biagiotti J, Valentini L, et al, Dynamic mechanical and Raman spectroscopy studies on interaction between single-walled carbon nanotubes and natural rubber. J Appl Polym Sci. 2004;92:3394-3400.

13. Lateef AA, Harthi MA, Atieh MA. Arab J Sci Eng. 35:49-56.

14. Bokobza L, Multiwall carbon nanotube-filled natural rubber: Electrical and mechanical properties. Express Polym Lett. 2012;6:213-223.

15. Zaidi Mat Desa MS, Hassan A, Arsad A. Adv Mater Res. 2013;747:639642 .

16. Lorenz H, Fritzsche J, Dasb A, et al. Advanced elastomer nanocomposites based on CNT-hybrid filler systems. Compos Sci Technol. 2009;69:2135-2143.

17. Cataldo F, Ursini O, Angelini G. Nanotub Car N. 2009;17:38-54.

18. Tarawneh MA, Ahmad SH, Rasid R, et al. Sains Malays. 2011;40:725728.

19. Shanmugharaj AM, Bae JH, Lee KY, et al. Physical and chemical characteristics of multiwalled carbon nanotubes functionalized with aminosilane and its influence on the properties of natural rubber composites. Compos Sci Technol. 2007;67:1813-1822.

20. Al-Hartomy OA, Al-Ghamdi AA, Al-Salamy F, et al. Int J Polym Sci. 2012;2012:1-8.

21. Predeep P, Devasia D, Aneesh J, et al. Organic bistable memory device from natural rubber (cis 1,4 polyisoprene)/fullerene nanocomposite thin films. Microelectron Eng. 2013;107:54-57.
22. Khadom AE, Mohammed KH. J Appl Polym Sci. 2007;1:1-8.

23. Al-Hartomy OA, Al-Ghamdi AA, Shtarkova R, et al. Dielectric and Microwave Properties of Graphene Nanoplatelets /Carbon Black Filled Natural Rubber Composites. International journal of materials and chemistry. 2012;2:116-122.

24. Dong B, Zhang L, Wu Y. Influences of different dimensional carbonbased nanofillers on fracture and fatigue resistance of natural rubber composites. Polym Test. 2017;63:281-288.

25. Lua Y, Lia J, Yua H, et al. Plasma induced surface coating on carbon nanotube bundles to fabricate natural rubber nanocomposites. Polym Test. 2018;65:21-28.

26. Kang H, Tang Y, Yao L, et al. Fabrication of graphene/natural rubber nanocomposites with high dynamic properties through convenient mechanical mixing. Composites Part B. 2017;112:1-7.

27. Chaa JH, Shina GJ, Kanga MJ, et al. A study on the effect of electron acceptor-donor interactions on the mechanical and interfacial properties of carbon black/natural rubber composites. Composites Part B. 2018;136:143-148.

28. Scherill G, Lavorgna M Buonocore GG, Zhan YH, et al. Tailoring Assembly of Reduced Graphene Oxide Nanosheets to Control Gas Barrier Properties of Natural Rubber Nanocomposites. Mater Interfaces. 2014;6:2230-2234.

29. Song SH, Jeong HK, Kang YG. Preparation and characterization of exfoliated graphite and its styrene butadiene rubber nanocomposites. $J$ Ind Eng Chem. 2010;16:1059-1065.

30. Dasa A, Kasaliwal GR, Jurk R, et al. Rubber composites based on graphene nanoplatelets, expanded graphite, carbon nanotubes and their combination: A comparative study. Compos Sci Technol. 2012;72:19611967.

31. Kima JS, Yunb JH, Kimc I, et al. Electrical properties of graphene/SBR nanocomposite prepared by latex heterocoagulation process at room temperature. J Ind Eng Chem. 2011;17:325-330.

32. Schopp S, Thomann R, Ratzsch KR, et al. Macromol Mater Eng. 2013:111 .

33. Ozbas B, O’Neill CD, Richard A Register, et al. Multifunctional elastomer nanocomposites with functionalized graphene single sheets. $J$ Polym Sci B Polym Phys. 2012;50:910-916.

34. Laoui T. Fuller Nanotub Car N. 2013;21:89-101.

35. Zhou XW, Zhu YF, Liang J. Preparation and properties of powder styrene-butadiene rubber composites filled with carbon black and carbon nanotubes. Mater Res Bull. 2007;42:456-464.

36. Tsuchiya K, Sakai A, Nagaoka T, et al. High electrical performance of carbon nanotubes/rubber composites with low percolation threshold prepared with a rotation-revolution mixing technique. Compos Sci Technol. 2011;71:1098-1104.

37. Girun N, Ahmadun FR,Rashid SA, et al. Fuller Nanotub Car N. 2007;15:207-214.

38. Pedroni, Oviedo LGS, Rosolen MA, et al. Conductivity and mechanical properties of composites based on MWCNTs and styrene-butadienestyrene block ${ }^{\mathrm{TM}}$ copolymers. J Appl Polym Sci. 2009;112:3241-3248.

39. Xinlei Yan, Yasutaka Kitaham, Harumi Sato, et al. Laser heating effect on Raman spectra of styrene-butadiene rubber/multiwalled carbon nanotube nanocomposites. Chem Phys Lett. 2012;523:87-91.

40. Das A, Stockelhuber KW, Jurk R, et al. Modified and unmodified multiwalled carbon nanotubes in high performance solution-styrenebutadiene and butadiene rubber blends. Polymer. 2008;49:5276-5283.

41. Peddini SK, Bosnyak CP, Henderson NM, et al. Nanocomposites 
from styrene-butadiene rubber (SBR) and multiwall carbon nanotubes (MWCNT) part 1: Morphology and rheology. Polymer. 2014;55:258270 .

42. Peddini SK, Bosnyak CP, Henderson NM, et al. Nanocomposites from styrene-butadiene rubber (SBR) and multiwall carbon nanotubes (MWCNT) part 2: Mechanical properties. Polymer. 2015;56:443-451.

43. Costa P, Silva J, Anson-Casaos A, et al. Effect of carbon nanotube type and functionalization on the electrical, thermal, mechanical and electromechanical properties of carbon nanotube/styrene-butadienestyrene composites for large strain sensor applications. Composites: Part B. 2014;61:136-146.

44. Roy K, Mandal SK, Md NA, et al. J Sol-Gel Sci Technol. 2016;77:718726.

45. Harandi MH, Alimoradi F, Rowshan G, et al. Morphological and mechanical properties of styrene butadiene rubber/nano copper nanocomposites. Results in Physics. 2017;7:338-344.

46. Salimi A, Naderi G, Khorshidi VG, et al. A comparative study on dispersion of carbon nanotubes in (styrene-butadiene rubber)-based nanocomposites. J Vinyl Addit Techn. 2017;23:28-34.

47. Shooli SA, Tavakoli M. Styrene Butadiene Rubber/Epoxidized Natural Rubber (SBR/ENR50) Nanocomposites Containing Nanoclay and Carbon Black as Fillers for Application in Tire-Tread Compounds. $J$ Macromol Sci B. 2016;55:969-983.

48. Bokobza L. Multiwall carbon nanotube elastomeric composites: A review. Polymer. 2007;48:4907-4920.

49. Chen B, Ma N, Bai X, et al. Effects of graphene oxide on surface energy, mechanical, damping and thermal properties of ethylene-propylenediene rubber/petroleum resin blends. RSC Advances. 2012;2:4683-4689.

50. Allahbakhsh A, Mazinani S, Kalaee MR, et al. Cure kinetics and chemorheology of EPDM/graphene oxide nanocomposites. Thermochim Acta. 2013;563:22-32.
51. Dubey KA, Bhardwaj YK, Rajkumar K, et al. J Polym Res. 2012;19:1-9.

52. Jin W, Kader MA, Ko WB, et al. Effects of UV irradiation on physicomechanical properties of EPDM/buckminsterfullerene composite. Polym. Adv Technol. 2004;15:662-668.

53. Nabil H, Ismail H, Azura AR. Properties of natural rubber/recycled ethylene-propylene-diene rubber blends prepared using various vulcanizing systems. Iran Polym J. 2014;23:37-45.

54. Amin M, Nasr GM, Ramzy GH, et al. Dielectric Properties of Butyl rubber/graphite powder composites in bulk and membrane forms. Mater Environ Sci. 2013;4:709-714.

55. Kumar SK, Castro M, Saiter A, et al. Development of poly(isobutyleneco-isoprene)/reduced graphene oxide nanocomposites for barrier, dielectric and sensingapplications. Mater Lett. 2013;96:109-112.

56. Yang J, Tian M, Jia QX, et al. Improved mechanical and functional properties of elastomer/graphite nanocomposites prepared by latex compounding. Acta Mater. 2007;55:6372-6382.

57. Kueseng P, Oui PS, Sirisinha C, et al. Anisotropic studies of multi-wall carbon nanotube (MWCNT)-filled natural rubber (NR) and nitrile rubber (NBR) blends. Polym Test. 2013;32:1229-1236.

58. Wang L, Ning N, Zhanga L, et al. Filler dispersion evolution of acrylonitrile-butadiene rubber/graphite nanocomposites during processing. Composites: Part A. 2013;47:135-142.

59. Malas A, Das CK. Influence of modified graphite flakes on the physical, thermo-mechanical and barrier properties of butyl rubber. $J$ Alloys Compd. 2017;699:38-46.

60. Zhang Y, Cho UR. Polym Compos. 2017:1-9. 